\title{
EL MANIFIESTO DE FERNANDO CHUECA GOITIA. ALGUNAS CONSIDERACIONES EN TORNO A LA AUTORÍA DEL MANIFIESTO DE LA ALHAMBRA
}

\author{
JAVIER MARTíNeZ GonZÁLEZ \\ Universidad de Navarra \\ jmartinezg@unav.es
}

\begin{abstract}
El Manifiesto de la Alhambra (1953) es uno de los textos más singulares de la historiografía arquitectónica española del siglo XX. Esta condición le ha hecho objeto de diversos estudios, ninguno de los cuales ha llegado a abordar con detenimiento la cuestión de su autoría. Aunque el Manifiesto venía firmado por veinticuatro arquitectos españoles, uno de ellos -Fernando Chueca Goitia- lo consideró siempre como obra suya. Entonces, ¿a quién debe atribuirse realmente el texto? ¿A los veinticuatro firmantes, o a uno solo de ellos? El estudio de la trayectoria e intereses del arquitecto e historiador español y, principalmente, el análisis detenido de la composición y contenido del texto, permite establecer el papel que Chueca Goitia desempeñó en la génesis del Manifiesto de la Alhambra, y valorar en qué medida y hasta qué punto pudo considerarlo una obra suya.
\end{abstract}

Palabras clave: Manifiesto de la Alhambra; Fernando Chueca Goitía; Autoría; Arquitectura española siglo XX.

\section{FERNANDO CHUECA GOITIA'S MANIFESTO}

The Manifesto of the Alhambra (1953) is among the most remarkable texts in the historiography of $20^{\text {th }}$-century Spanish architecture. This status has made it the subject of several studies, none of which has carefully addressed the question of its authorship. Although the Manifesto was signed by 24 Spanish architects, one of them -Fernando Chueca Goitiaconsidered himself to be its author. So, to whom should the text really be attributed: to the 24 signatories, or to only one of them? By studying Chueca Goitia's career and through a careful analysis of both the composition and content of the text, this article attempts to show the role played by Fernando Chueca Goitia in the genesis of the Manifesto of the Alhambra, and the extent to which he could claim authorship of the text.

Key words: Manifesto of the Alhambra; Fernando Chueca Goitia; Authorship; $20^{\text {th }}$-century Spanish architecture.

Desde diversos puntos de vista, el Manifiesto de la Alhambra que veinticuatro arquitectos españoles lanzaron a la luz en 1953 puede considerarse un texto excepcional (fig. 1). Excepcional por infrecuente, pues responde a un género que no tenía precedentes en la literatura arquitectónica española de la época. Y excepcional también porque, frente al proverbial individualismo hispánico, constituye una declaración conjunta de un grupo de profesionales, una especie de frente común y unitario en relación a la dirección que debería tomar la arquitectura española en aquellos momentos. Quizá sea esta condición peculiar del texto la responsable de que, todavía sesenta años después de su redacción, continúe atrayendo la atención tanto de arquitectos, como de historiadores de la arquitectura. Y aunque, como se verá, la propuesta contenida en sus páginas pueda considerarse 


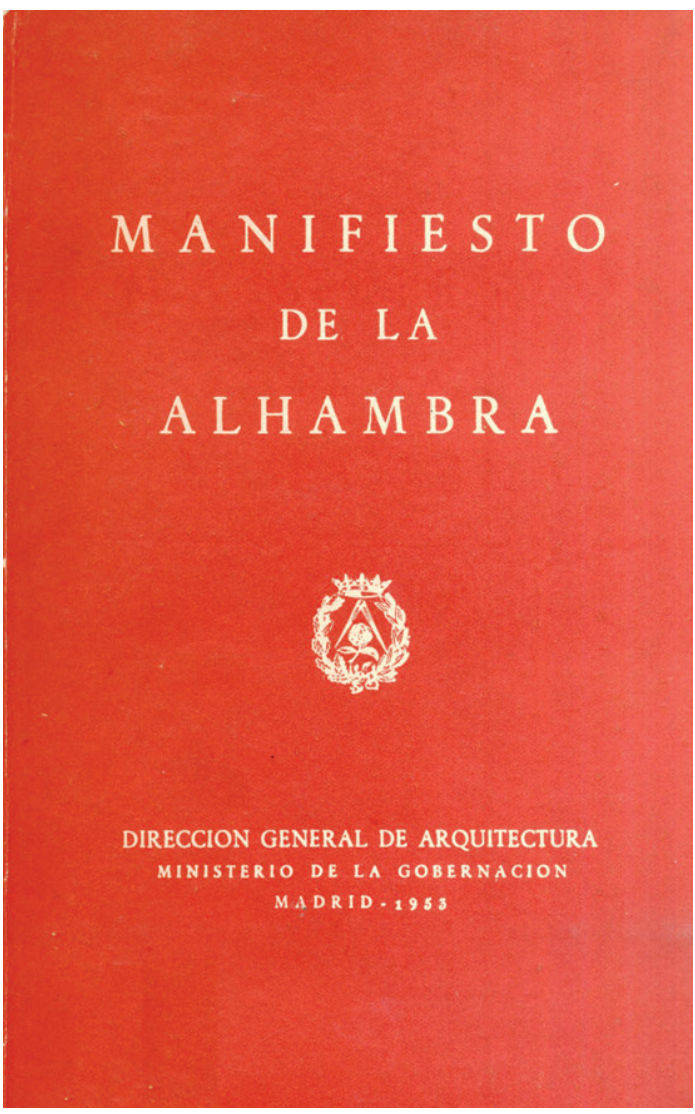

Fig. 1. Manifiesto de la Alhambra. Madrid: Dirección General de Arquitectura, 1953. Portada.

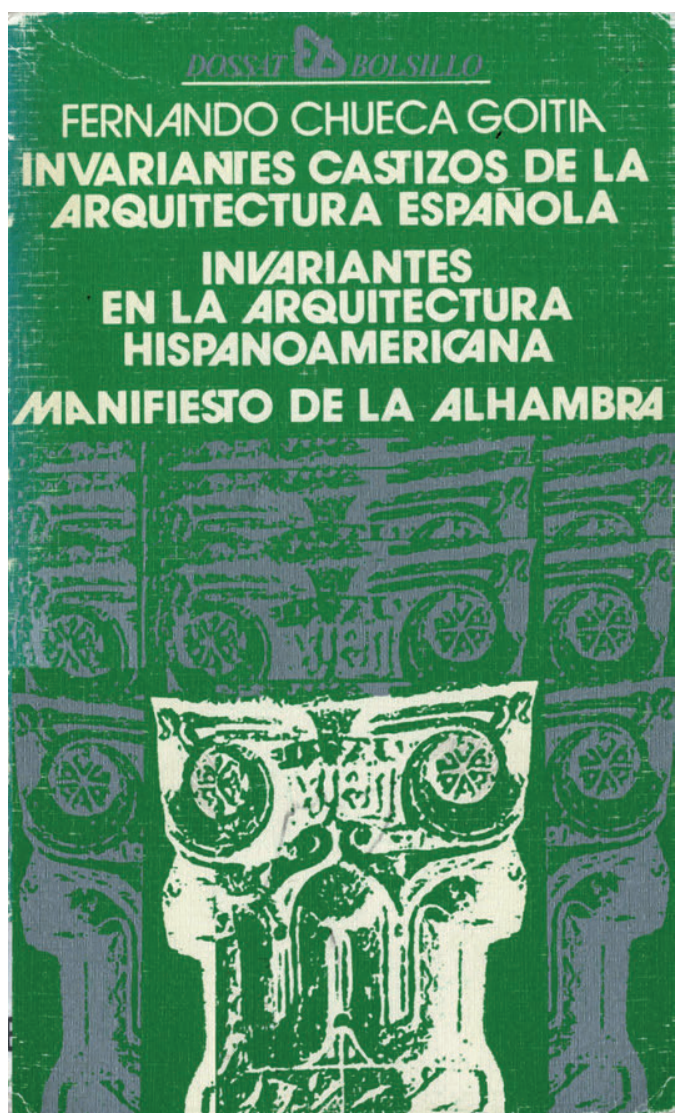

Fig. 2. Fernando Chueca Goitia. Invariantes castizos de la arquitectura española. Invariantes de la arquitectura hispanoamericana. Manifiesto de la Alhambra. Portada de la edición de Dossat de 1981.

fallida, el Manifiesto nunca ha dejado de ocupar un lugar destacado en la historiografía de la arquitectura española de posguerra.

Este carácter distintivo y singular del texto hace que todavía resalte más lo inadvertida que ha pasado una cuestión clave: la de su autoría. Podría quizá pensarse que, por obvia, no era necesario prestarle especial atención: los autores del Manifiesto de la Alhambra serían, lógicamente, los veinticuatro arquitectos que lo suscribieron. De este modo, todos los profesionales que estamparon su firma en el texto podrían considerarse, legítimamente y en igual medida, coautores del mismo. Sin embargo, esta aparente certidumbre parece verse comprometida cuando uno de ellos -Fernando Chueca Goitia - se presenta a sí mismo como el autor del texto. Y ello abiertamente, sin conciencia alguna de estar apropiándose de algo que no le pertenece. Hasta tal punto consideraba el Manifiesto una obra de su propiedad que, pasados los años, la reeditó nuevamente junto a otros escritos suyos, en un volumen donde él figuraba como único autor (fig. 2).

Tuve la oportunidad de preguntar a Fernando Chueca Goitia por las razones de esta 'apropiación'. Fue pocos meses antes de su muerte, mientras se encontraba convaleciente de una operación en su casa de Madrid. Me respondió con enorme naturalidad que se debía a que lo había escrito 
él, y pasó a hablar de otra cosa, no como quien se siente incómodo con algo y prefiere cambiar de tema sino, más bien, como el que piensa que poco más se puede añadir a lo dicho, porque la cuestión no da más de sí.

De este modo, tanto los hechos como las palabras de Chueca ponen sobre la mesa algunos interrogantes: ¿a quién hay que atribuir entonces la redacción del Manifiesto de la Alhambra? ¿A los veinticuatros arquitectos firmantes, o a uno solo de ellos? ¿Qué papel desempeñaron entonces los otros veintitrés? Y, sobre todo, ¿en qué medida podía Chueca considerar el texto como suyo y hasta qué punto era esto cierto? ${ }^{1}$

Tratar de dar respuesta a estas preguntas es el objetivo de este artículo. Para ello, trataré en primer lugar de presentar someramente la figura de Fernando Chueca Goitia. A continuación, me referiré al viaje a la Alhambra que se encuentra en la génesis del Manifiesto. Y, por último, intentaré analizar con detenimiento el contenido del texto, abordando por separado las dos partes que lo componen: el extenso ensayo introductorio que condensaba su propósito e intenciones y el estudio de los diversos valores del monumento granadino que se ofrecían a modo de 'Conclusiones' del texto.

\section{Fernando Chueca Goitia}

La de Fernando Chueca Goitia constituye una de esas figuras cuya biografía resulta difícilmente abarcable. Julián Marías, con quien le unía una gran amistad desde la década de los años treinta, recordaba cómo el catálogo de materias que "interesa[ba]n a Fernando Chueca (y la intensidad de ese interés, que llega al apasionamiento) era interminable"2. Tratar de abordar, siquiera de manera somera, una aproximación a su vida y a su obra, desborda con mucho los límites de este artículo, por lo que referiré únicamente unas pocas notas de su trayectoria profesional, destinadas principalmente a mostrar el lugar que ocupaba el arquitecto e historiador madrileño en la escena arquitectónica española en el momento de la redacción del Manifiesto ${ }^{3}$.

Chueca Goitia nació en Madrid, el 29 de mayo de 1911. Obtuvo el título de arquitecto en 1936, pocas semanas antes del estallido de la guerra civil. La destrucción del legado arquitectónico de la capital española que pudo contemplar durante los tres años de contienda contribuyó a que se afirmara en él una clara inclinación hacia la historia de la arquitectura y la restauración de monumentos, tareas a las que dedicaría una parte importante de su actividad profesional. Al terminar la guerra, la imposibilidad de ejercer como arquitecto -fue objeto de depuración profesional durante un tiempo- forzó su dedicación a tareas de investigación histórica. Así, los años cuarenta fueron testigos del interés de Chueca por la historia y la teoría de la arquitectura, de manera especial aunque no exclusivamente- la de los siglos XVII y XVIII. En los estudios que llevó a cabo durante este periodo, ampliamente difundidos en publicaciones como Archivo Español de Arte o Revista de ideas estéticas, se encuentran ya algunas de las cuestiones que abordaría con mayor detenimiento en 1947, en las páginas de Invariantes castizos de la arquitectura española. Este texto, uno de los más conocidos e influyentes de su larga trayectoria, tenía una doble condición: por un lado, resultaba una especie de decantación de diversas ideas e intuiciones que habían ido bullendo en la

\footnotetext{
${ }^{1}$ Mi intención es, por tanto, dar un paso más en la definición del papel esencial desempeñado por Fernando Chueca en la redacción del Manifiesto de la Alhambra, una cuestión ya apuntada por Ángel Isac (1993 y 2006) y que yo mismo dejé pendiente de explicar en otra ocasión (Martínez González, 2006).

${ }^{2}$ Marías, 1992: 18.

${ }^{3}$ Quien esté interesado en conocer más a fondo la trayectoria personal y profesional del arquitecto e historiador español, puede consultar AA.VV, 1992, en especial el artículo de Pedro Navascués contenido en ese volumen.
} 
cabeza del arquitecto durante los años precedentes: por otro, incoaba otras que, a su vez, serían más extensamente abordadas con posterioridad, a lo largo de las páginas del Manifiesto.

Durante los casi seis años transcurridos entre Invariantes castizos de la arquitectura española y la publicación en 1953 del Manifiesto de la Alhambra, Fernando Chueca continuó desarrollando una abundante actividad en distintos frentes. El levantamiento de las sanciones impuestas por la Dirección General de Arquitectura le posibilitó comenzar a edificar sus primeras obras de arquitectura, todavía de pequeñas dimensiones. Por aquellas mismas fechas, empezó a interesarse también por cuestiones de carácter urbanístico, vinculándose como docente al Instituto de Estudios de Administración Local. Y llevó a cabo una larga estancia de investigación -casi un año- en los Estados Unidos, becado por la Academia de Bellas Artes de San Fernando. Pero, sobre todo, continuó escribiendo.

Aunque disminuyó sustancialmente la redacción de artículos para publicaciones periódicas en concreto, Chueca abandonó casi por completo sus colaboraciones con las revistas del CSIC-, durante el intervalo 1949-1953 el historiador español dio a la imprenta una media de dos libros al año. El primero fue, en 1949, la biografía de uno de sus arquitectos de referencia, Juan de Villanueva. En 1950, apareció la traducción que Chueca había llevado a cabo de la History of Spanish Architecture publicada por Bernard Bevan en 1938. En 1951 vinieron Planos de ciudades iberoamericanas y filipinas existentes en el Archivo de Indias, en colaboración con Leopoldo Torres Balbás, El semblante de Madrid, y La catedral nueva de Salamanca. Al año siguiente, un Guión de Arquitectura sobre el Museo del Prado y el primero de los dos libros a los que dio lugar su estancia en el continente americano, Viviendas de renta reducida en los Estados Unidos. Por fin, en 1953 aparecieron Nueva York: forma y sociedad, un largo escrito en el que recogía las impresiones de su estancia en la ciudad del Hudson y el volumen correspondiente a la arquitectura española del siglo XVI en la Historia Universal del Arte Hispánico.

Toda esta actividad profesional -de manera singular, su producción escrita-contribuyó a que la figura de Fernando Chueca alcanzase una posición singular en el horizonte teórico y crítico de la arquitectura española. En el panorama de una disciplina estrechamente vinculada a la práctica, cualquier labor de reflexión teórica, máxime si llegaba a formularse por escrito con cierta brillantez y continuidad, difícilmente podía pasar inadvertida. Así, pronto se le adjudicó a Chueca "el primer lugar [entre] nuestros publicistas de arquitectura", la autoría de "los más importantes estudios de arquitectura conocidos hasta ahora en España" y la consideración de "auténtica cumbre" en la geografía de la literatura arquitectónica española ${ }^{6}$. Todavía muchos años después, Rafael Aburto consideraría un "favor" que Chueca, "un profesional, un erudito, historiador del arte y esas cosas" hubiera compendiado las reflexiones suscitadas en la Alhambra redactando el Manifiesto ${ }^{7}$ y Carlos de Miguel insistiría de nuevo en que sus "dotes de crítico de arquitectura, escritor y conferenciante no [tenían] par entre los arquitectos españoles"8. Por ello, no parece excesivo atribuir a Chueca una cierta posición de liderazgo en la cultura arquitectónica de la época. Registrar este hecho permite advertir mejor el papel dirigente que Chueca desempeñó en la génesis del Manifiesto 9 .

\footnotetext{
${ }^{4}$ S.A., 1947: 40.

${ }^{5}$ Massot, 1952: 38.

6 AA.VV., 1956: 72. Son palabras de Carlos de Miguel. 2005).

${ }^{7}$ Bergera, 2003: 138, n. 14 (esta cita no se encuentra en el texto resultante de la publicación de la tesis: Bergera,

${ }^{8}$ Miguel, 1972: 10.

${ }^{9}$ Resultaría, sin embargo, ingenuo atribuir únicamente al extenso curriculum de Chueca el ascendiente que pudiera haber logrado sobre el resto de profesionales del momento. Ese hecho debe entenderse acompañado del empuje, capacidad de crítica y compromiso con la disciplina que caracterizó el conjunto de su trayectoria.
} 


\section{El viaje a Granada y las sesio- nes en la Alhambra}

El Manifiesto de la Alhambra fue el resultado de las jornadas de estudio del monumento nazarí llevadas a cabo en Granada, los días 14 y 15 de octubre de 1952. Estas jornadas, a su vez, se enmarcaban dentro de lo que había empezando a denominarse Sesiones de Crítica de Arquitectura, unas reuniones periódicas de arquitectos donde se presentaban y analizaban conjuntamente edificios o cuestiones relacionadas con la arquitectura. Impulsadas y animadas por el director de la Revista Nacional de Arquitectura, las Sesiones estaban abiertas a la participación de cualquier profesional de la disciplina, con el único requisito de solicitar previamente tomar parte en ellas ${ }^{10}$. Puesto que estas reuniones tenían lugar casi siempre en Madrid, lo cierto es que la inmensa mayoría de quienes las frecuentaron fueron profesionales de la capital. Por eso mismo, y aunque su contenido era transcrito y publicado en las páginas de la Revista Nacional de Arquitectura, su ámbito de influencia natural -si bien, no exclusivo- fue también el panorama arquitectónico madrileño.

La Sesión de Crítica de Arquitectura

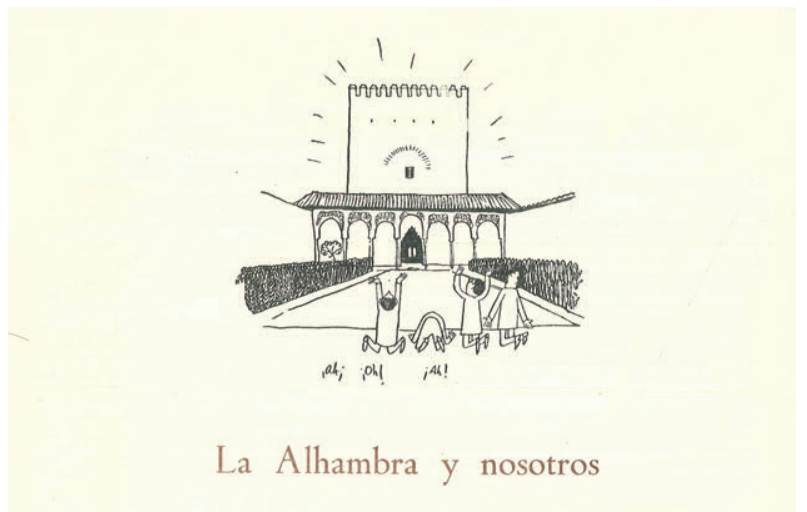

Un grupo de arquitectos convocado por las Sesiones de Crítica de Arquitectura ha celebrado unas reuniones en Granada, más concretamente en la Alhambra, para estudiar el célebre palacio árabe desde un punto de vista puramente arquitectónico, al objeto de sacar unas enseñanzas, si ello era posible, útiles a nuestro diario trabajo profesional.

En la convocatoria, que se repartió en su momento, el arquitecto Fernando Chueca expresó, en las palabras que siguen, el propósito de las reuniones granadinas.

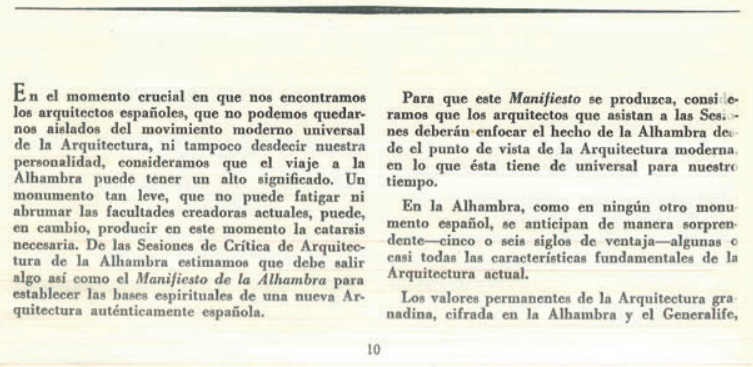

Fig. 3. Fernando Chueca Goitia. «La Alhambra y nosotros». Boletín de Información de la Direccion General de Arquitectura, diciembre 1952. sobre La Alhambra poseía al menos dos particularidades. La primera, que proponía analizar no una obra recientemente construida, como solía ser lo habitual, sino otra de una época muy anterior. Y, la segunda, que requería el desplazamiento hasta Granada de quienes desearan tomar parte ella. Por este motivo, pero también -y principalmente- por las altas expectativas que algunos de los asistentes habían depositado en esas sesiones, su desarrollo se preparó concienzudamente. Fernando Chueca Goitia se encargó de redactar un texto a modo de convocatoria, al que dio por título "La Alhambra y nosotros" 11 , donde expuso el propósito de las sesiones (fig. 3). Resulta muy significativo que dejase recogido en él de manera expresa lo que debería surgir de aquellas jornadas: la redacción de un manifiesto que sirviera para establecer las "bases espirituales de una nueva arquitectura auténticamente española" ${ }^{\prime 2}$, para el que, incluso, apuntaba ya un título -"algo así como el Manifiesto de la Alhambra"13.

${ }^{10}$ Para que llegase a conocimiento de todos los arquitectos, que podían inscribirse y formar parte de ellas, desde la redacción de la revista se enviaba, al comienzo de cada curso, una circular a los Colegios recordando esta cuestión.

${ }^{11}$ Chueca, 1952a: 10-13. Puede encontrarse también en AA.VV, 1953: 13-15.

${ }^{12}$ Chueca, 1952a: 13

${ }^{13}$ Chueca, 1952a: 10. 


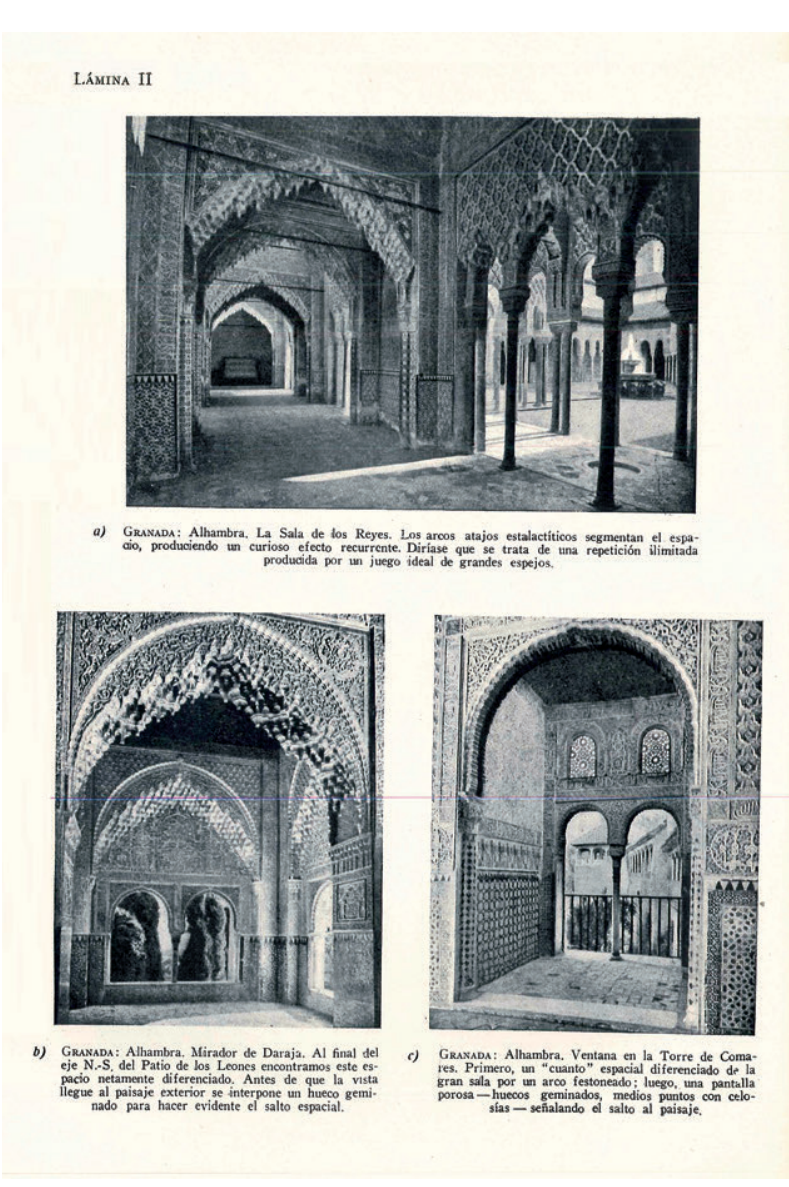

Fig. 4. Fernando Chueca Goitia. Invariantes castizos de la arquitectura española. Madrid: Dossat, 1947. Algunas de las muchas referencias a la Alhambra que contiene el libro.
La convocatoria elaborada por Chueca contenía el esquema de trabajo a seguir durante las jornadas granadinas. Se establecía en ella la división de los asistentes en cuatro grupos, cada uno de los cuales centraría su atención en uno de los conjuntos de valores -humanos, naturales, formales o mecánicos-del monumento nazarí. Al final de la jornada, cada equipo debería exponer ante los otros la labor desarrollada, exposición a la que seguiría un debate general sobre el tema ${ }^{14}$. De vuelta a Madrid, los grupos redactarían unas conclusiones finales y las entregarían a un coordinador que se encargaría de ordenarlas y darles su forma definitiva. A la Dirección General de Arquitectura le correspondería la publicación del documento final, que sería repartido de manera gratuita "a todos los arquitectos, autoridades de la vida artística de la nación y críticos de arte en general""15. El articulado del programa terminaba anunciando que el Manifiesto iría firmado por todos los asistentes, para exponer de modo claro que se trataba de "una posición doctrinal de amplia base"16.

El carácter tan concreto y definido con el que se idearon las jornadas granadinas contrasta con el discurrir habitual, mucho menos estructurado y sistemático, de las Sesiones de Crítica de Arquitectura. Este modo de actuar evidenciaba el deseo de los organizadores de que no quedase en saco roto las cues-

tiones que iban a tratarse, pretendiendo de asegurar así el carácter operativo de lo que allí teóricamente iba a gestarse. Digo teóricamente, porque aquello que debía gestarse en Granada hacía tiempo que había visto la luz, al menos en la cabeza de Fernando Chueca Goitia.

El viaje que los arquitectos españoles realizaron a la Alhambra lo había llevado a cabo el historiador español bastante tiempo atrás, al menos desde que en 1947 publicó Invariantes castizos de la arquitectura española. En las páginas de este escrito, el palacio nazarí había sido presentado como el ejemplo superlativo de la presencia de esas invariantes en un edificio español (fig. 4). Chueca había encontrado en él una síntesis de algunos de los aspectos más relevantes del hacer

${ }^{14}$ Se concretaba incluso la conveniencia de contar con un taquígrafo que tomara nota de los debates generales.

15 Chueca, 1952a: 13.

${ }^{16}$ Chueca, 1952a: 13. No obstante, se concedía que si alguno de los asistentes se mostraba en desacuerdo con el texto final, podría retirar su firma del mismo. 
arquitectónico propiamente español. Pero, además, había descubierto también el valor permanente -ni temporal, ni caduco- de la arquitectura contenida en aquellos palacios y fortalezas. Y con él, la capacidad de convertirse en un referente válido para la arquitectura del momento presente. Este era el mensaje encerrado tras los muros de la Alhambra, un mensaje que, como se ha dicho, Chueca había descubierto bastante tiempo atrás ${ }^{17}$. En ese sentido, no necesitaba volver allí. Solo la ocasión de amplificar los ecos de ese mensaje -y qué mejor modo de hacerlo que a través de un Manifiesto- parecía requerir su viaje 'de regreso' a Granada.

\section{Los veinticuatro firmantes}

Los asistentes a las jornadas granadinas no formaban un grupo demasiado numeroso (fig. 5). $\mathrm{Y}$ se ha hablado de que las ausencias son tanto o más elocuentes que las presencias ${ }^{18}$. De alguna de las primeras se puede dar razón sin hacer excesivas cábalas: ya se ha comentado que, al tratarse de una Sesión de Crítica de Arquitectura, era necesario estar admitido como asociado para poder tomar parte en ella. Hay que pensar, por tanto, que los participantes saldrían de los habituales a esas reuniones. De los veinticuatro firmantes, sabemos con certeza que al menos diez tomaban parte en ellas con cierta asiduidad ${ }^{19}$, pero no puede decirse lo mismo de los catorce restantes. Si es verdad que no todos los habituales de las Sesiones viajaron a Granada ${ }^{20}$, también lo es que no todos los que viajaron a Granada asistían habitualmente a las Sesiones.

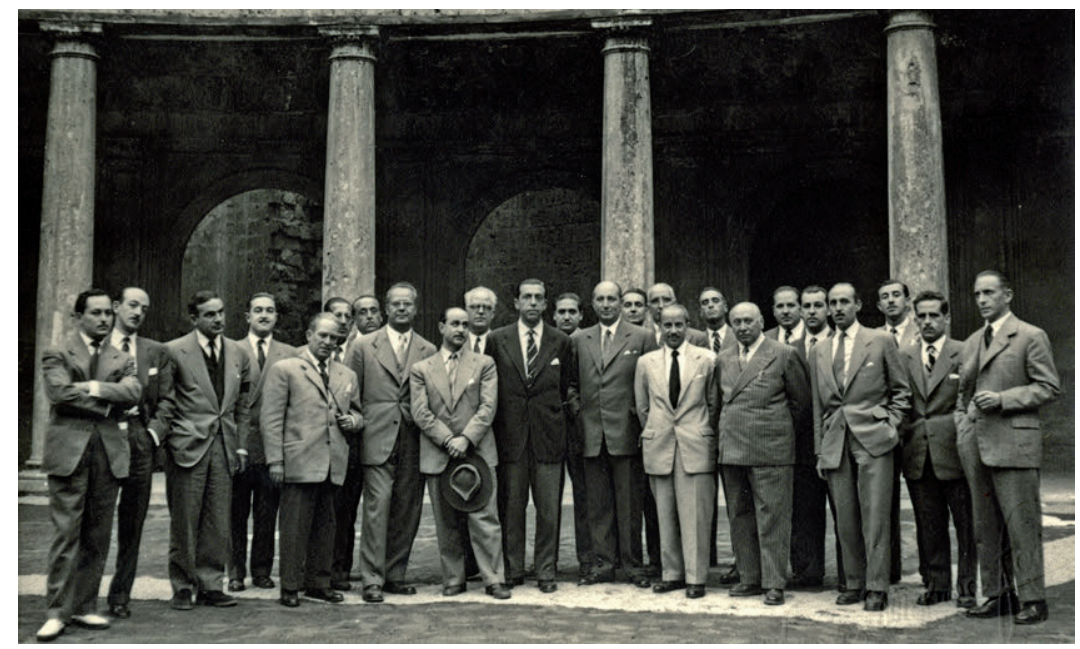

Fig. 5. Asistentes a las Sesiones de Crítica de Arquitectura de la Alhambra. Archivo General de la Universidad de Navarra. Fondo Rafael Aburto. Conviene notar que en la imagen aparecen veinticuatro personas, pero entre ellas no se encuentra Juana Ontañón, la única mujer entre las firmantes del texto.

${ }^{17}$ En ese sentido, como Chueca se encargó de recordar, el Manifiesto constituía tan solo "una ampliación y más extensa confrontación de las mismas teorías" contenidas en Invariantes castizos de la arquitectura española (Chueca, 1981: 13). Como ha señalado Ángel Isac (1993: 39), el texto granadino venía también así "a demostrar la validez y certeza del método contenido en su escrito de 1947".

${ }^{18}$ Véase, por ejemplo, Fullaondo/Muñoz, 1997: 194

${ }^{19}$ Hay constancia de la participación en Sesiones de Crítica anteriores -quedaron recogidas algunas intervenciones suyas en las páginas de la Revista Nacional de Arquitectura- de Rafael Aburto, Pedro Bidagor, Francisco de Asís Cabrero, Fernando Chueca, Miguel Fisac, Ricardo Magdalena, Carlos de Miguel, Francisco Prieto Moreno, Manuel Romero Aguirre y Secundino Zuazo.

${ }^{20}$ Faltaban, por ejemplo, Luis Moya, Luis Gutiérrez Soto o Víctor d'Ors. 
En cualquier caso, el grupo lo componían veinticuatro profesionales ${ }^{21}$, apenas un tres por ciento de los arquitectos colegiados en Madrid por aquellas fechas ${ }^{22}$. Si, como se pretendía, el manifiesto resultante debía representar "una posición doctrinal de amplia base"23, ese exiguo porcentaje parecía invalidar tal pretensión. En cualquier caso, sí es cierto que se trataba de una muestra amplia, al menos en cuanto a las edades de quienes la componían: desde sexagenarios como Secundino Zuazo -el de mayor edad y ascendiente de los asistentes- hasta quienes acababan de cumplir los treinta, como José Luis Picardo, Juana Ontañón o Emilio Larrodera ${ }^{24}$. El núcleo más numeroso lo integraban aquellos profesionales que se encontraban en torno a los cuarenta. A este grupo pertenecía Chueca, y algunos otros de los impulsores de las jornadas, como Francisco Prieto Moreno o Carlos de Miguel $^{25}$. Aunque la distancia de edad que les separaba del resto no era demasiada, se veían a sí mismos -así, al menos, lo afirmaba Chueca- como miembros de una "generación central, equidistante entre los que llegan y los que se van" ${ }^{26}$. Situarse en una posición intermedia era un modo de afirmar su idoneidad para la tarea que debía llevarse a cabo en Granada: a los de más edad se les había pasado ya el tiempo -se estaban yendo- y los más jóvenes, que estaban todavía llegando, necesitaban ganar en experiencia ${ }^{27}$.

Los veinticuatro arquitectos que viajaron a la Alhambra también podrían conformar una muestra hasta cierto punto representativa del conjunto de la profesión, en cuanto que no constituían un grupo demasiado homogéneo en sus planteamientos. Había entre ellos cierta diversidad de pareceres, que se puso de manifiesto en relación incluso a cuestiones tan básicas como el sentido de la visita al monumento granadino. Frente al entusiasmo de algunos, hay que mencionar también el escepticismo de otros. Entre estos últimos, seguramente el más explícito fue Francisco de Asís Cabrero, quien se planteó incluso la idoneidad de un edificio antiguo para servir de modelo a la arquitectura contemporánea: "Yo me pregunto: siguiendo a la Alhambra, ¿vamos a la arquitectura

${ }^{21}$ Lo formaban Rafael Aburto, Pedro Bidagor, Francisco de Asís Cabrero, Eusebio Calonge, Fernando Chueca, José Antonio Domínguez Salazar, Rafael Fernández Huidobro, Miguel Fisac, Damián Galmés, Luis García Palencia, Fernando Lacasa, Emilio Larrodera, Ricardo Magdalena, Manuel López Mateos, Antonio Marsá, Carlos de Miguel, Juana Ontañón, José Luis Picardo, Francisco Prieto Moreno, Francisco Robles, Mariano Rodríguez Avial, Manuel Romero Aguirre y Secundino Zuazo.

${ }^{22}$ Los arquitectos pertenecientes al Colegio Oficial de Arquitectos de Madrid en 1952 eran 738 (Vázquez, 1974: 86).

${ }^{23}$ Chueca, 1952a: 13.

${ }^{24}$ Estuvo presente incluso un estudiante de Arquitectura, José Luis Aranguren, que no firmó el Manifiesto.

${ }^{25}$ En este punto, querría aclarar una cuestión: al destacar el papel fundamental desempeñado por Fernando Chueca tanto en la génesis como en la redacción del Manifiesto y centrarme únicamente en su figura, no pretendo insinuar que el resto de los firmantes fueran poco menos que convidados de piedra en toda aquella 'operación' (aunque alguno, de hecho, lo fuera). Eso significaría pasar por alto el papel que pudieron jugar algunos otros profesionales, como Carlos de Miguel -impulsor de las Sesiones de Crítica de Arquitectura- y, de manera singular, Francisco Prieto Moreno. Prieto Moreno - quien, por otro lado, tenía una notable afinidad de planteamientos con Chueca-, alentó y facilitó el desarrollo de aquellas jornadas en su doble papel de Arquitecto Conservador de la Alhambra y de Director General de Arquitectura. Sin embargo, los documentos y testimonios que nos han llegado muestran a las claras el destacado protagonismo de Fernando Chueca Goitia, tanto en las jornadas de Granada como, todavía mucho más, en lo que constituye su legado: el $M a$ nifiesto de la Alhambra en sí.

${ }^{26}$ Chueca Goitia, 1953a: 6.

${ }^{27}$ Chueca todavía desconfiaba un poco de los profesionales de menor edad: su falta de "experiencia y serenidad" podía convertirlos en presas fáciles de un "internacionalismo enteramente privado de raíces propias" (Chueca Goitia, 1953a: 7), lo que constituía para Chueca la peor de las amenazas. De hecho, el arquitecto e historiador español se encontraba en general más cómodo -intelectualmente hablando- en compañía de arquitectos de cierta edad. Mucho tiempo después, recordaría que eran seguramente Secundino Zuazo (nacido en 1887), Pedro Bidagor (nacido en 1906) y Francisco Prieto Moreno (nacido en 1907) aquellos firmantes del Manifiesto con los que mayor afinidad de pensamiento tenía (Martínez, 2004). 
nueva? Hoy todo es distinto que en la época en que este palacio se construyó. ¿Cómo vamos a seguir esto de aquí? La Alhambra era un palacio para vagos redomados" ${ }^{28}$.

Las notas que nos han quedado de aquellas jornadas ${ }^{29}$ ponen de manifiesto también que, a pesar del esfuerzo de quienes las impulsaron, los intercambios de opiniones no siempre resultaron productivos. Unas veces, porque se detuvieron en aspectos hasta cierto punto menos relevantes, como el mismo nombre del manifiesto ${ }^{30}$. Y otras, bien porque se perdían en generalizaciones excesivas, bien por el motivo contrario, al extraer de lo observado aplicaciones directas para la práctica profesional, cuando lo que se trataba era -como también insistía Chueca- de penetrar "el sentido y la intención" de La Alhambra".

\section{El contenido del Manifiesto de la Alhambra}

\section{Las conclusiones de los grupos de trabajo}

Como se ha indicado anteriormente, los veinticuatro asistentes se dividieron en cuatro grupos, cada uno de los cuales analizaría uno de los valores de la Alhambra. Tras una puesta en común de lo estudiado con el resto de los asistentes, redactarían ya en Madrid unas conclusiones de las que saldría el texto definitivo. Al final, ya fuera porque juzgó que esas conclusiones no tenían entidad suficiente, ya porque hubiera decidido hacerlo así desde el principio, Chueca dispuso que la parte nuclear del Manifiesto no fueran estas 'Conclusiones', sino una extensa introducción -enteramente redactada por él- que dispuso que las antecediera. De este modo, las contribuciones de los cuatro equipos de arquitectos quedaron de hecho relegadas a una posición de segundo orden en el conjunto del Manifiesto.

Sin embargo, el análisis de este apartado del texto presenta bastante interés. Al comparar las conclusiones de los grupos recogidas en el Manifiesto, con las que cada uno de ellos entregó a Fernando Chueca para la redacción final del texto, es posible ver la sintonía de cada uno de los equipos con los planteamientos del arquitecto e historiador español. Cuanto mayor era esa sintonía, más se parecía el texto publicado en las 'Conclusiones' al redactado por los equipos. Cuanto menor, mayor era la distancia entre uno y otro, pues Chueca se veía 'obligado' a introducir modificaciones para que el texto que había recibido reflejase mejor al espíritu del Manifiesto.

José Luis Aranguren, Rafael Fernández Huidobro, Luis García Palencia, Francisco Moreno López y Mariano Rodríguez Avial componían el primero de los equipos, el dedicado a estudiar los aspectos constructivos de la Alhambra (fig. 6). Sintetizaron sus conclusiones en un exhaustivo y detallado escrito. En él, describieron pacientemente las unidades de obra de los palacios nazaríes, desde la cimentación hasta las bóvedas de ladrillo y las cubiertas y techos de madera; detallaron pacientemente las distintas fábricas; estudiaron con detenimiento los aleros, los zócalos y las yese-

${ }^{28}$ AA.VV., 1953: 23. En términos semejantes se expresaron también más adelante, ya en Madrid, algunos asociados a las Sesiones de Crítica de Arquitectura que no acudieron a Granada. Luis Pérez Mínguez opinaba, por ejemplo, que la Alhambra constituía exclusivamente una lección de cómo, "con unos medios modestísimos, se pueden conseguir los más excelentes resultados cuando se trata de crear un ambiente agradable a los sentidos", pero que no era precisamente éste "el problema fundamental que t[enía] planteada actualmente la Arquitectura". Menos positivas eran las declaraciones de Ramón Aníbal Álvarez -"Yo voy a hablar mal de la Alhambra, de la que tengo una pobre impresión. No me gusta nada. [...] En frío, ahora, mis recuerdos no enlazan con estas cosas que habéis contado"-, o de José Yarza: "Creo, como resumen de mi impresión en este viaje [recientemente realizado a Granada por su cuenta], que no puede sacarse de la Alhambra absolutamente nada" (AA.VV., 1953: 49-50).

${ }^{29}$ Recogidas en AA.VV., 1953, pp. 20-46.

${ }^{30}$ AA.VV., 1953: 24.

31 AA.VV., 1953: 22. 


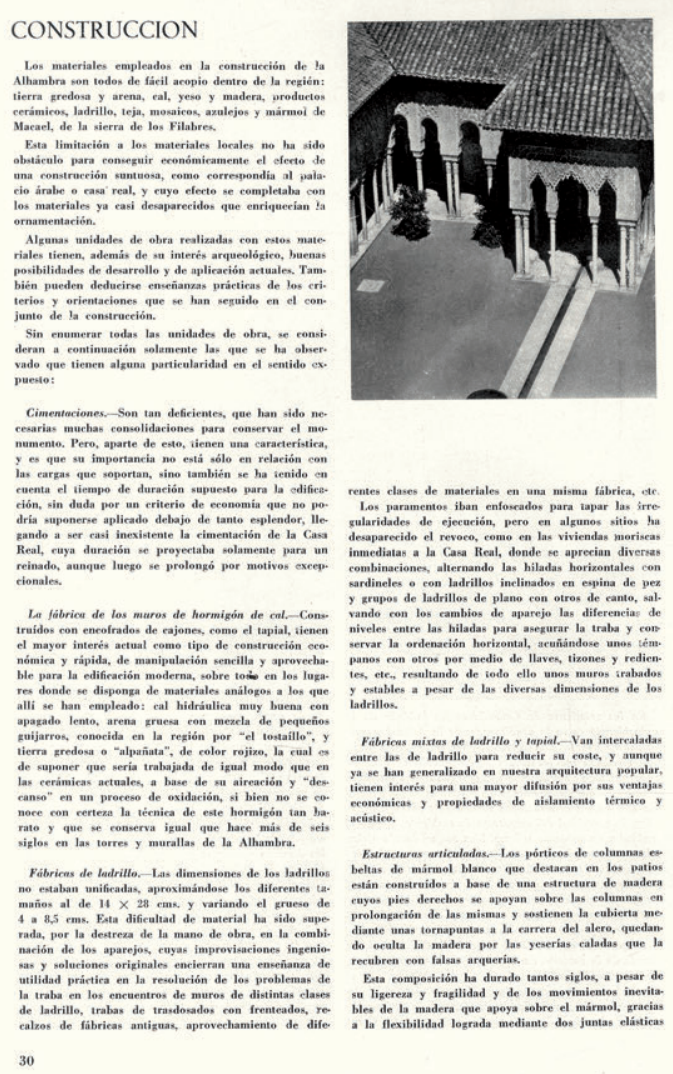

Fig. 6. Conclusiones del grupo de trabajo 'Construcción'. Revista Nacional de Arquitectura, 136, abril 1953. rías, etc. El texto rebosaba conocimientos y capacidad de observación, pero dejaba traslucir una notable ingenuidad en su continuo afán por extraer enseñanzas prácticas aplicables de manera directa a la arquitectura actual. El resultado fue que Fernando Chueca apenas lo tuvo en cuenta a la hora de redactar el apartado "Construcción" del Manifiesto (fig. 7).

Ocho arquitectos componían el siguiente grupo, "Formas". Era el más numeroso y tenía como integrantes más significativos a Pedro Bidagor y Secundino Zuazo ${ }^{32}$. El texto que redactaron incidía sobre los aspectos compositivos de la Alhambra, tanto los que sólo eran perceptibles desde el interior (dimensiones de patios y estancias, escalonamiento de las proporciones, contrastes y armonías entre ambientes), como los que podían advertirse exteriormente (adaptación a la topografía, simplicidad formal de los volúmenes, etc.). $\mathrm{Su}$ escrito establecía las semejanzas y diferencias que mostraba la Alhambra con respecto a la arquitectura contemporánea y proponía una serie de cuestiones que podrían incorporarse a la práctica moderna, la mayor parte de ellas en relación al planeamiento urbanístico contemporáneo. Chueca respetó bastante el contenido de estas conclusiones, incluyendo un buen número de ellas en el correspondiente apartado del $M a$ nifiesto $^{33}$ (fig. 8).

"Decoración" era la cuestión que debía abordar el tercero de los equipos. Lo integraban Rafael Aburto, Francisco de Asís Cabrero, Eusebio Calonge, Carlos de Miguel y José Luis Picardo. Las conclusiones se recogieron en un texto que redactó Rafael Aburto y que llevó por título "Razones de la Alhambra" (fig. 9). Con un lenguaje a medio camino entre lo lírico y lo fílosófico, Aburto abordó una serie de cuestiones relacionadas con los aspectos decorativos del palacio granadino. La primera mitad del texto la dedicó a ensalzar el papel del agua en la imaginaria liturgia que tenía lugar en el monumento. Después, el escrito abordaba cómo los motivos fuertemente geométricos de techos y paredes remitían a un orden trascendente y eterno así como el modo particular en que la decoración alhambrina era abstracta: no tanto por una prohibición impuesta por la religión islámica, sino por obedecer a una profunda convicción de sus creadores. Esta última cuestión fue la

\footnotetext{
32 José Antonio Domínguez Salazar, Damián Galmés, Emilio Larrodera, Ricardo Magdalena, Antonio Marsá y Manuel Romero completaban el equipo.

${ }^{33}$ Los epígrafes II-V del texto del Manifiesto son, prácticamente, trascripción exacta de diversos párrafos de las conclusiones del grupo de trabajo 'Formas'.
} 

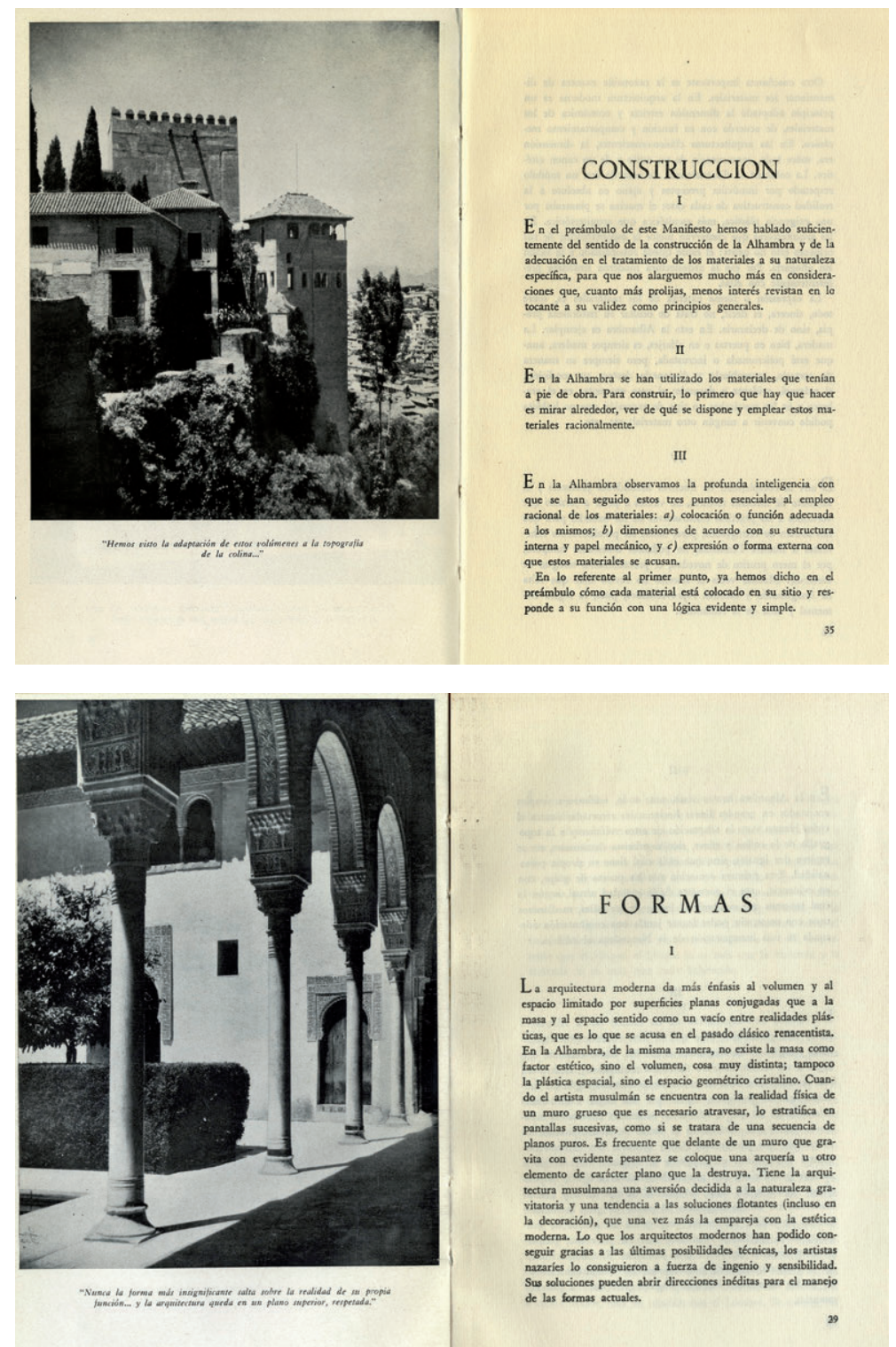

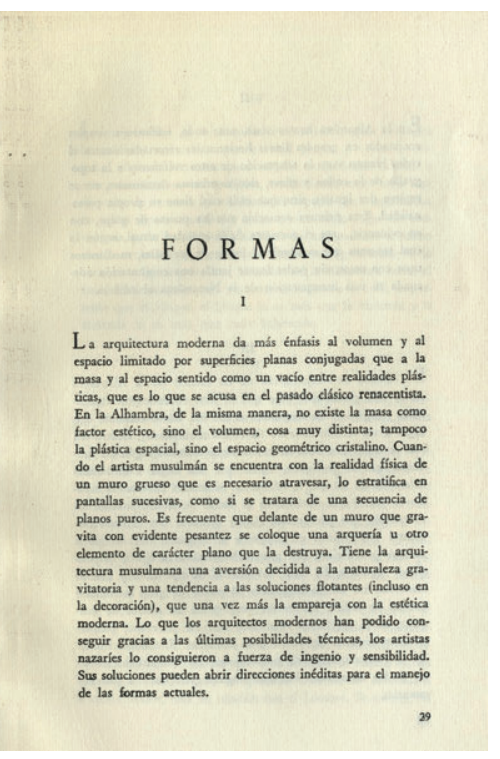

Fig. 7. Apartado 'Construcción' del Manifiesto de la Alhambra.
Fig. 8. Apartado 'Formas' del Manifiesto de la Alhambra.

única que Chueca tuvo en cuenta a la hora de redactar el apartado correspondiente del Manifiesto ${ }^{34}$ (fig. 10). El resto de consideraciones incluidas en él se alejaron por completo del esquema trazado por Aburto.

Hasta cierto punto, no es de extrañar que Chueca obrase así, pues había estudiado ya por su cuenta la decoración alhambrina y había llegado a forjarse su propia opinión al respecto. De hecho,

34 "La decoración de la Alhambra es abstracta", decía Aburto en su escrito. Y continuaba: "Más que a una absoluta prohibición de representar seres animados, obedece (como corresponde por alguna excepción aislada) a una profunda convicción" (Aburto, 1953: 41). Y en el Manifiesto quedó recogido: "La decoración de la Alhambra es abstracta. Mucho se ha escrito sobre las prohibiciones coránicas, pero como explicación esto no basta. Tenía que existir previamente en la mentalidad de estos pueblos un desdén por la imagen antropológica de las cosas" (Chueca Goitia, 1953a: 29). 


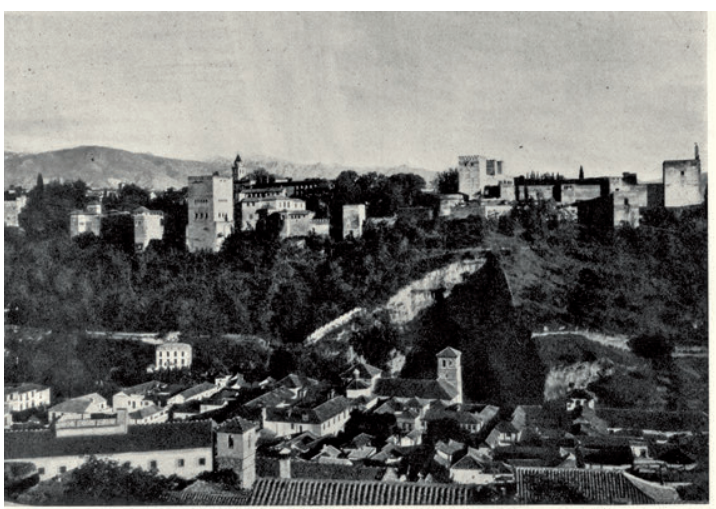

RAZONES DE LA ALHAMBRA

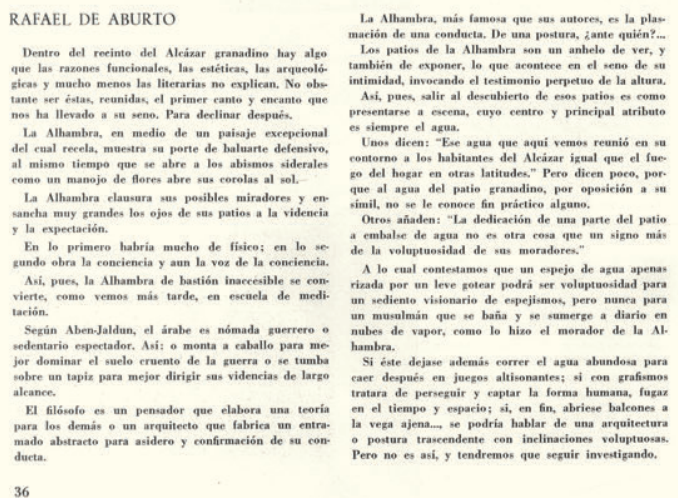

Fig. 9. Rafael Aburto. «Razones de la Alhambra». Revista Nacional de Arquitectura, 136, abril 1953.

algunos años antes había expuesto las que juzgaba sus notas más características en Invariantes castizos. De este texto suyo rescató alguna de las ideas que vertió en este apartado del Manifiesto, por ejemplo la referida a cómo la decoración era "extraordinariamente respetuosa con la arquitectura" 35 , o se encontraba "localizada en lugares determinados" $"$ ". Sin embargo, se mostró muy cauto en relación a la cuestión de la ornamentación referida a la arquitectura que estaba por venir. Elogió la postura "inteligente y extraordinariamente sagaz" adoptada a este respecto por el movimiento racionalista-la "decoración por omisión, [que] obtiene valores decorativos del propio desnudo"-, y recomendó abstenerse por el momento de lenguajes decorativos hasta que no consiguiera darse con uno adecuado ${ }^{37}$.

Por último, debe hacerse referencia al grupo que se ocupó de estudiar los jardines de la Alhambra. Lo componían Miguel Fisac, Fernando Lacasa, Francisco Prieto-Moreno y el propio Chueca. El texto que prepararon como conclusión de su trabajo fue sustancialmente el que dio lugar al apartado "Jardines" del $M a$ nifiesto (fig. 11). Quedó recogido en él el tema de la casa como jardín y el jardín como casa, y cómo se anticipaba así en La Alhambra la introducción de la naturaleza en la arquitectura característica de la vivienda moderna, donde "son paisajes reales los que penetran del suelo al techo mediante los grandes ventanales" ${ }^{38}$. Asimismo, se refería el modo en que el agua adoptaba en la Alhambra "tres estados naturales: el momento de surgir o manantial, el de fluir y el de estancarse" ${ }^{\prime 39}$ y su concreción formal en "formas elementales y perfectas": el manantial es el círculo, el movimiento es la recta, la quietud es el rectángulo. Y, por último, concluía afirmando cómo correspondía a la geometría no

\footnotetext{
${ }^{35}$ Chueca Goitia, 1953a: 41. En Invariantes castizos se explicaba que "una decoración vigorosa y de fuerte modelado destruiría la limpidez del volumen cúbico. Para que las formas prismáticas se impongan es menester conservar la tersura de sus caras" (Chueca, 1947: 47).

${ }^{36}$ Chueca Goitia, 1953a: 42.

37 "Quede, pues, sentado que este manifiesto no recomienda orientación alguna en materia tan delicada, y que el mejor consejo que por ahora puede darse es el de abstenerse" (Chueca Goitia, 1953a: 39-40).

${ }^{38}$ Chueca Goitia, 1953a: 48.

${ }^{39}$ Chueca Goitia, 1953a: 48. También este aspecto había quedado recogido en el texto previo: "El árabe considera los tres momentos del agua: el agua surge, el agua circula, el agua se estanca" (AA.VV., 1953: 34).
} 


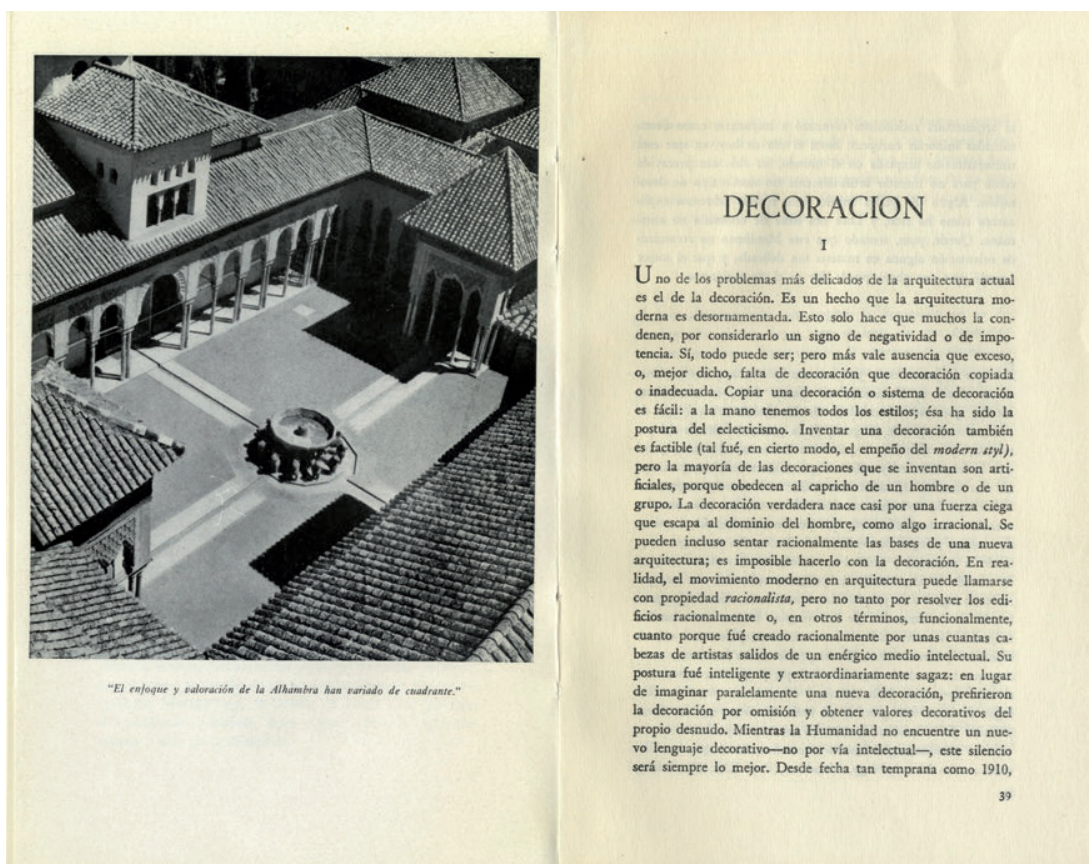

Fig. 10. Apartado

'Decoración' del Manifiesto de la Alhambra.

sólo la tarea de engastar el agua en el jardín, sino también, en un clima como el nuestro, la de recrear la totalidad del paisaje, motivo suficiente para tomar el jardín hispanomusulmán como "punto de partida de nuestra jardinería" ${ }^{40}$.

\section{El 'verdadero' contenido del Manifiesto}

A pesar de ocupar casi la mitad de la extensión del Manifiesto, las páginas dedicadas a los cuatro aspectos anteriormente indicados eran, en cierto sentido, bastante prescindibles. Ha resultado de interés dedicarles aquí un espacio porque reflejan cómo Chueca fue modelando las contribuciones del resto de los participantes hasta que adquirieron los perfiles deseados por él. Su labor no fue sólo la de resumirlas dándoles forma literaria sino que, como he procurado mostrar, rehizo algunas y omitió otras, eliminó lo que en ellas no fue de su gusto y agregó lo que juzgó oportuno, acentuó determinados matices y relegó otros a un segundo plano, etc.. Pero era en realidad la primera parte del escrito -compuesta enteramente por el historiador español- la verdaderamente importante, aquella que poseía mayor carga y densidad propositiva. Hasta tal punto constituía el núcleo del escrito que con ella, afirmaba, "podría terminar el Manifiesto, ya que su mensaje espiritual ha[bría] quedado expresado" 41 .

Chueca quiso empezar esas páginas con una breve descripción de la arquitectura española durante el último siglo transcurrido, donde identificó cuatro momentos significativos. En primer lugar, las realizaciones del siglo XIX, en ocasiones mediocres, pero poseedoras de un equilibrio

\footnotetext{
${ }^{40}$ Chueca Goitia, 1953a: 49.

41 "Lo que sigue -continuaba Chueca- no son más que observaciones sugeridas por el monumento y por el cambio de impresiones que tuvimos en las jornadas de trabajo sostenidas en la propia colina Roja" (Chueca Goitia, 1953a: 26).
} 


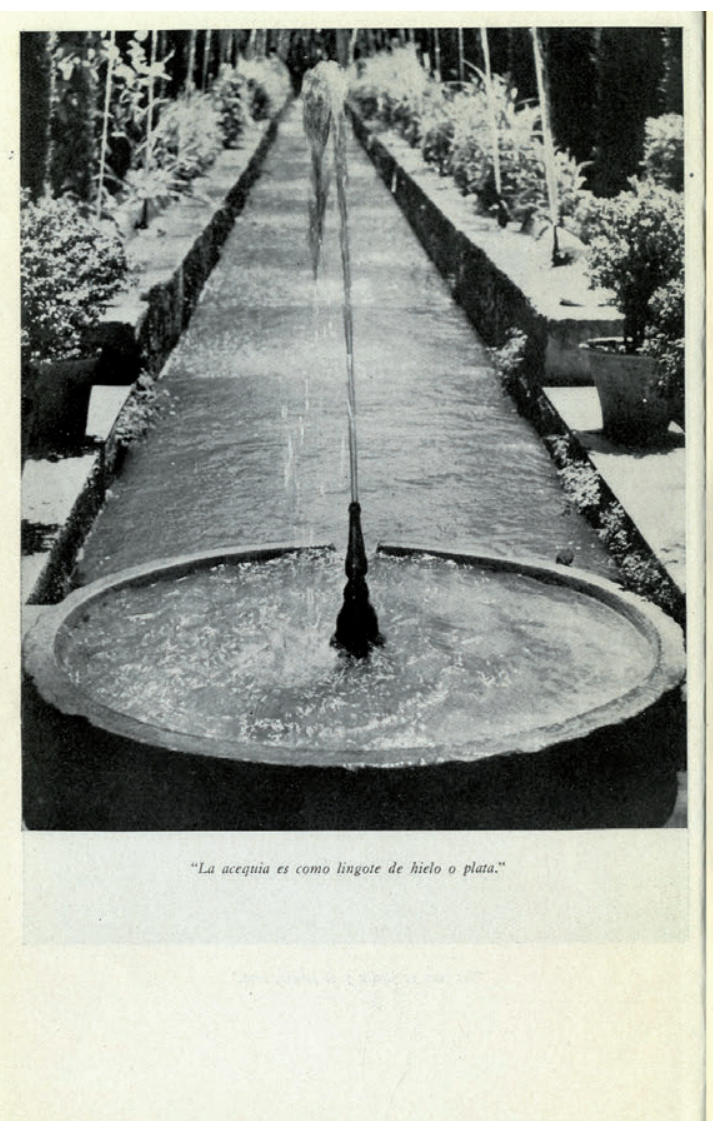

\section{JARDINES}

I

$\mathrm{E}_{1}$ jardín musulmán es, ante todo, un intento de representar el Paraíso en la Tierra. El empeño no puede ser más excelente. Un pueblo que vive de sensaciones tenía que reaccionar así. El jardín árabe es casi teología, y se describe como anuncio de la otra vida en el Corán. Los bienaventurados descansarán en pabellones como en bajeles que flotan entre verdura $y$ aguas limpias y frescas. Lo más refinado del escenario son estos pabellones y miradores para la vida quiescente; por ellos, el jardín se embebe en la casa, o la casa se desparrama en el jardín. La misma Sala de Comares no es sino el mayor y más noble La misto pabellon de toda ba Casa Real vicja, donde la vista es solicitad desde los cuatro puntos cardinales. Si el jardín es el Paraíso, la casa debe acercarse lo más posible a su apariencia, y en seguida nos damos cuenta de que la casa es jardín y el jardín, casa.

Las yeserías son como plantas trepadoras de gayos colores, y Las yeserías son como plantas trepadoras de gayos colores,
por todos los huecos se cuela el jardín, con su vegetación, su murmullo, su olor. El jardín, a su vez, se acota y se limita como una estancia habitable cuyo techo es el azul. No es el jardín abierto al infinito de las cortes absolutas, el jardin que parece pensado para que el Rey Sol, poniendo ruedas a su

Fig. 11. Apartado 'Jardines' del Manifiesto de la Alhambra.

y un tono medio que luego había sido imposible recuperar. Posteriormente, el fervor nacionalista que acompañó a la crisis del 98, responsable de una exhumación precipitada y, lógicamente, superficial de los estilos del pasado español ${ }^{42}$. En tercer lugar, ya en los albores de la República, Chueca distinguió una corriente internacionalista que, sin embargo, pronto se debilitó "por falta de verdadero arraigo". Finalmente, un postrer brote de nacionalismo -"el que todavía perdura"habría surgido con el advenimiento del régimen de Franco, aunque ya había sido ensayado con anterioridad. Chueca lo juzgó con mayor benevolencia que los anteriores tradicionalismos, reconociéndole el mérito de "su apetencia-casi lograda- de unanimidad" y de "su respeto a la dignidad material de las construcciones". Con todo, esta tendencia apuntaba ya a un fin cercano: "sus postulados se resquebraja[ba]n", y "los supuestos formales y estéticos sobre los que se fundó no representa[ba]n ya nada" para las nuevas generaciones de arquitectos que abandonaban las aulas ${ }^{43}$. A los ojos de Chueca, la arquitectura española se encontraba en un momento de crisis, entendida esta tanto en su sentido negativo -agotamiento y desorientación-, como en lo que tenía de positivo

${ }^{42}$ En esos momentos sólo emergía "un pequeño islote verdaderamente importante de arte creador" de la escuela catalana. Chueca Goitia, 1953a: 4.

${ }^{43}$ Chueca Goitia, 1953a: 5. 
-la necesidad de imprimirle un nuevo rumbo, más acorde con lo que se juzgaba conveniente para ella. De hecho, era la inminencia de "esa revolución que se avecina[ba]" la que había urgido a Chueca a tomar partido en una dirección determinada y a tratar de movilizar con él a otros arquitectos españoles.

En esa tesitura histórica, la propuesta contenida en el Manifiesto incidía en la necesidad de asentarse firmemente en "el subsuelo racial", en el ser de España. Solo una vez establecido ese sólido cimiento, podrían las realizaciones españolas buscar la expresión propia de su época e incorporarse "a la corriente universal de la arquitectura". Y la clave para hacerlo, estaba "ahí, en la Alhambra" Por eso, al recordar, cuarenta años después, las intenciones que habían guiado la composición del Manifiesto, Chueca se refería a la proclamación de "un movimiento nacionalista" de una propuesta enraizada en el seno de aquello que constituía la nación española. Este movimiento, para alejarse del peligro internacionalista debería anclarse fuertemente en la tradición, lo que le salvaría igualmente de caer en el extremo opuesto, el tradicionalismo. Así, era en la búsqueda de lo genuinamente español -"no sólo en la arquitectura, sino en el ser de España, en su manera de sentir y de expresar el arte, en su manera más radical de ser ella misma" su principal razón de ser toda la 'operación' liderada por Chueca. Así quedaba formulado con claridad al comienzo del Manifiesto: "Lo que nos dicen los últimos años de nuestra historia artística es que por encima de todo se impone el afán de encontrarnos a nosotros mismos" ${ }^{\text {"47 }}$. En el fondo, y contemplando las cosas desde una perspectiva más amplia, el Manifiesto sería únicamente una expresión más de aquello que constituyó la médula de la trayectoria profesional y vital de Fernando Chueca: la consideración "obsesiva sobre el ser español, sobre España"

La única particularidad del escrito granadino, debida lógicamente también al pensamiento de Chueca, era el modo concreto en que debía llevarse a cabo el intento de regeneración de la arquitectura española: por medio de la "incorporación [a ella] del arte hispanomusulmán" ". El texto alhambrino hacía suyas unas palabras de Emilio García Gómez, según las cuales "en España ser arabista es profundizar en nuestra historia y descubrir vetas inexploradas en nuestra propia vida" Chueca quiso seguir los pasos de algunos músicos y pensadores que se acercaron al mundo islámico español sin nostalgias ni exotismos. En el campo de la arquitectura esto resultaba algo novedoso, "una tradición increíblemente inédita" ${ }^{51}$ y, por ello, idónea para encontrar "caminos y veredas olvidados" por los que pudiera discurrir la arquitectura española desde ese momento en adelante $^{52}$ (fig. 12). En este punto como en otros, Fernando Chueca había ido nuevamente por delante, descubriendo hacía mucho tiempo ya la actualidad del monumento nazarí y presentándolo como un modelo de referencia al resto de los profesionales del momento.

\section{Qué le vamos a hacer}

Como se sabe, el Manifiesto terminó demostrándose un proyecto fallido, a pesar del entusiasmo que llegaría a suscitar entre algunos profesionales. En unas reuniones celebradas en Madrid

\footnotetext{
${ }^{44}$ Chueca Goitia, 1953a: 25.

45 Chueca, 1993: 11.

${ }^{46}$ Chueca, 1993: 11.

${ }^{47}$ Chueca Goitia, 1953a: 7.

${ }^{48}$ Fernández Alba, 1992: 43.

49 Chueca Goitia, 1953a: 24.

${ }^{50}$ García Gómez, 1948.

51 Así se referiría a ella Juan Antonio Gaya Nuño (1954: 9).

${ }^{52}$ Chueca Goitia, 1953a: 17.
} 


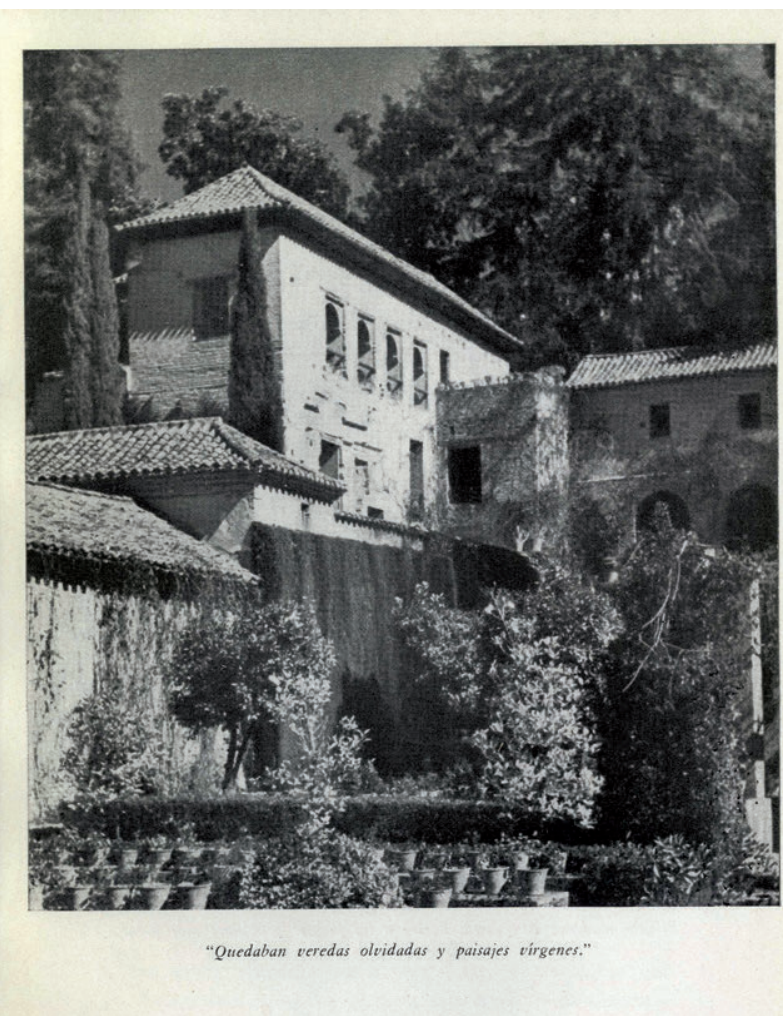

Fig. 12. «No hemos sabido descubrir las posibilidades ocultas de la arquitectura hispanomusulmana...». Manifiesto de la Alhambra. a la vuelta de Granada, José María Muguruza auguraba, por ejemplo, que la importancia de esa iniciativa sería enorme, mayor incluso de la que podían advertir quienes suscribieron el texto. En realidad, y aunque así hubiera sido, tampoco hubiera resultado fácil medir la huella que pudo dejar un texto cuya única propuesta concreta radicaba en hacer una "visita de peregrinación" a la Alhambra ${ }^{53}$. Es cierto que Carlos de Miguel, quizá uno de los firmantes más entusiastas del texto alhambrino, creyó ver aplicados sus principios en la casa Ugalde, de Coderch y Valls ${ }^{54}$, seguramente una de las obras más significativas de la arquitectura española de la segunda mitad de siglo XX (fig. 15). También lo es que otros arquitectos presentes en las sesiones, como Rafael Aburto o Miguel Fisac, parecieron acusar fuertemente el impacto producido por el edificio granadino $^{55}$. E, incluso, que un personaje como Oriol Bohigas, completamente extraño al mundo en el que se gestó al Manifiesto, asegurase haber descubierto, si bien una década más tarde, la verdadera trascendencia del texto ${ }^{56}$.

Sin embargo, fue el propio Fernando Chueca -nadie más autorizado que él para hacerlo- quien reconoció que el Manifiesto no había cosechado los frutos deseados. Con motivo de la primera edición conjunta de Invariantes castizos de la arquitectura española, Manifiesto de la Alhambra e Invariantes en la arquitectura hispanoamericana, el historiador español confesaba que, a pesar de que esos escritos

${ }^{53}$ Chueca Goitia, 1953a: 26.

${ }^{54}$ En diciembre de 1953 publicó en la Revista Nacional de Arquitectura un artículo en el que algunos pasajes del Manifiesto acompañaban la exposición de varias fotografías de la casa (Miguel, 1953). En realidad, la vivienda en Caldetas había sido construida con anterioridad a la aparición del texto de Chueca. Sobre la casa Ugalde y el Manifiesto de la Alhambra, puede consultarse Rovira, 2006.

${ }^{55}$ La influencia de las sesiones de Granada en la obra de Rafael Aburto ha sido abordada por Bergera (2005), especialmente el epígrafe "Aprendiendo de la Alhambra”, 103-115. Sobre Miguel Fisac y la Alhambra: Fisac, 1997.

También arquitectos extranjeros, como Luis Barragán, han sabido captar las lecciones contenidas en el palacio nazarí y recogidas en el texto granadino. Puede consultarse, por ejemplo, el intento de análisis de la obra del arquitecto mexicano con base en los postulados del Manifiesto de la Alhambra llevado a cabo por Antonio Garza (1995), de manera particular el capítulo "Del Manifiesto de la Alhambra a la Carta de Guadalajara", 275-325.

${ }_{56}$ Bohigas, 1962a: 6-7. El 'descubrimiento' del Manifiesto por parte del arquitecto catalán debe entenderse en el marco de su reivindicación a favor de una arquitectura realista - "única posibilidad de continuación y vitalización del racionalismo"-, que venía llevando a cabo desde hacía unos años y que alcanzó su expresión más acabada en el manifiesto "Cap a una arquitectura realista", publicado tan sólo unos meses antes (Bohigas, 1962b). 
continuaban vigentes en su ánimo, no parecía que pudiese afirmarse lo mismo con relación al ámbito más extenso de su "pública aceptación" 57 . Con el discurrir del tiempo, Chueca fue percibiendo que el rumbo que tomaba la arquitectura española de la segunda mitad del siglo XX, se desviaba progresivamente del que él hubiera querido para ella, precisamente aquel que tenía su hoja de ruta en el Manifiesto. Por eso, pasados los años, el veterano historiador debió conformarse únicamente con "la mínima satisfacción de que algunas de sus ideas removieron el pensamiento ajeno" y "enriquecieron el hacer arquitectónico, incorporando una nueva terminología" ${ }^{58}$.

En la conversación -ya referida anteriormente- mantenida con quien firma estas líneas, el ya anciano arquitecto quería recordar que había sido Félix Candela quien le confió cómo, a la hora de proyectar su casa, había procurado poner su mente en el Manifiesto de la Alhambra. Sin embargo, a continuación, como sin querer encontrar consuelo en ese recuerdo, reconocía: "Evidentemente él [Candela] intentó buscar, pero fue una cosa esporádica que no cuajó en la medida en que yo hubiera deseado. No cuajó entre los arquitectos españoles. [...] Si ha sido así, ¿qué le vamos a hacer?" 59 . Una decepción que acompañó al historiador español hasta el final de sus días y que constituye una muestra más, la postrera, de los estrechos vínculos que unían a Chueca con el Manifiesto, al autor con su obra.

\section{BIBLIOGRAFÍA}

AA.VV. (1953): «Sesión de Crítica de Arquitectura. Sesiones celebradas en la Alhambra durante los días 14 y 15 de octubre de 1952». En: Revista Nacional de Arquitectura, 136, Madrid, pp. 13-50.

AA.VV. (1956): "Sesión de Crítica de Arquitectura. Crítica de las Sesiones de Crítica de Arquitectura». En: Revista Nacional de Arquitectura, 176-177, Madrid, pp. 71-83.

AA.VV. (1992): Fernando Chueca Goitia: un arquitecto en la cultura española. Madrid: Fundación Antonio Camuñas.

AA.VV. (1998): Goya. Revista de arte, 264, Madrid (número monográfico con motivo de los cincuenta años de Invariantes castizos de la arquitectura española).

Aburto, Rafael (1953): "Razones de la Alhambra". En: Revista Nacional de Arquitectura, 136, Madrid, pp. 36-47.

Bergera, Iñaki (2003): Rafael Aburto, arquitecto [tesis doctoral]. Pamplona: Universidad de Navarra, 2003.

Bergera, Iñaki (2005): Rafael Aburto, arquitecto. La otra modernidad. Barcelona: Fundación Caja de Arquitectos.

Bevan, Bernard (1951): Historia de la arquitectura española. Barcelona: Juventud. Edición original: Bevan, Bernard (1938): History of Spanish Architecture. London: Batsford.

Bohigas, Oriol (1962a): “Granada, hoy”. En: Arquitectura, 45, Madrid, 3-15.

Bohigas, Oriol (1962b): “Cap a una arquitectura realista”. En: Serra d'Or, Barcelona, pp. 17-20.

Chueca Goitia, Fernando (1947): Invariantes castizos de la arquitectura española. Madrid: Dossat.

Chueca Goitia, Fernando (1951a): El semblante de Madrid. Madrid: Revista de Occidente.

Chueca Goitia, Fernando (1951b): La catedral nueva de Salamanca. Salamanca: Universidad.

Chueca Goitia, Fernando (1952a): "La Alhambra y nosotros". En: Boletín de Información de la Dirección General de Arquitectura, diciembre, Madrid, pp. 10-13.

Chueca Goitia, Fernando (1952b): El Museo del Prado. Madrid: Ínsula.

Chueca Goitia, Fernando (1952c): Viviendas de renta reducida en los Estados Unidos: un estudio de los conjuntos en gran escala y de sus repercusiones en materia de urbanismo. Madrid: Instituto de Estudios de Administración Local.

Chueca Goitia, Fernando (1953a): Manifiesto de la Alhambra. Madrid: Dirección General de Arquitectura.

Chueca Goitia, Fernando (1953b): Nueva York: forma y sociedad. Madrid: Instituto de Estudios de Administración Local.

Chueca Goitia, Fernando (1953c): Arquitectura del siglo XVI. Ars Hispaniae: Historia Universal del Arte Hispánico, vol. XI. Madrid: Plus Ultra.

\footnotetext{
${ }^{57}$ Chueca, 1981: 13.

${ }^{58}$ Chueca, 1981: 13-14.

${ }^{59}$ Martínez González, 2004.
} 
Chueca Goitia, Fernando (1981): "Prólogo a la segunda edición". En: Invariantes castizos de la arquitectura española; Invariantes en la arquitectura hispanoamericana; Manifiesto de la Alhambra. Madrid: Dossat.

Chueca Goitia, Fernando / Miguel, Carlos de (1949): La vida y las obras del arquitecto Juan de Villanueva. Madrid: Dirección General de Arquitectura.

Chueca Goitia, Fernando / Torres Balbás, Leopoldo (1951): Planos de ciudades iberoamericanas y filipinas existentes en el Archivo de Indias, 2 vols. Madrid: Instituto de Estudios de Administración Local.

Fernández Alba, Antonio (1992): "Entrevista a Fernando Chueca Goitia". En: AA.VV. (1992), Fernando Chueca Goitia: un arquitecto en la cultura española. Madrid: Fundación Antonio Camuñas, pp. 27-61.

Fisac, Miguel (1997): "Lo que he aprendido en la Alhambra”. En: Cánovas, Andrés, ed. (1997): Fisac, Madrid: Ministerio de Fomento, pp. 10-11.

Fullaondo, Juan Daniel / Muñoz, María Teresa (1997): Historia de la arquitectura contemporánea española. Y Orfeo desciende. Madrid: Molly Editorial.

García Gómez, Enrique (1948): Silla del Moro y Nuevas escenas andaluzas. Madrid: Revista de Occidente.

Garza, Antonio (1995): Mirar y transformar la herencia hispana en la arquitectura de Luis Barragán [tesis doctoral]. Pamplona: Universidad de Navarra.

Gaya Nuño, Juan Antonio (1954): “El Manifiesto de la Alhambra”. En: Ínsula, 97, Barcelona, p. 9 y p. 12.

Isac, Ángel (1993): "La visión arquitectónica de la Alhambra: el Manifiesto de 1953". En: Chueca Goitia, Fernando (1993): Manifiesto de la Alhambra. Granada: Fundación Rodríguez-Acosta.

Isac, Ángel (2006): “Una Sesión Crítica de Arquitectura en la Alhambra: El Manifiesto”. En: Isac, Ángel, ed. (2006): El Manifiesto de la Alhambra 50 años después. El monumento y la arquitectura contemporánea. Granada: Patronato de la Alhambra y Generalife, TF Editores, pp. 183-235.

Massot, F. (1952): "Fernando Chueca Goitia. Viviendas de renta reducida en los Estados Unidos". En: Boletín de Información de la Dirección General de Arquitectura, diciembre, Madrid, pp. 31-32.

Miguel, Carlos de (1953): "Villa en Caldetas". En Revista Nacional de Arquitectura, 144, Madrid, pp. 25-30.

Miguel, Carlos de (1972): "Recopilación de 25 años de la Revista Nacional de Arquitectura y de la revista Arquitectura (julio 1948-diciembre 1972)". En: Arquitectura, 169-170, Madrid, pp. 1-131.

Martínez González, Javier (2004): Conversación con Fernando Chueca Goitia [documento inédito]. Madrid, 27.IV.2004.

Martínez González, Javier (2006): "De Madrid a Granada pasando por Nueva York. La experiencia americana de Fernando Chueca y el Manifiesto de la Alhambra". En: Pozo, José Manuel / Martínez González, Javier, coords. (2006): La arquitectura americana, motor y espejo de la arquitectura española en el arranque de la modernidad (1940-1965). Pamplona: T6 Ediciones, pp. 175-184.

Navascués Palacio, Pedro (1992): “Arquitectura e Historia en la obra de Fernando Chueca”. En: AA.VV. (1992): Fernando Chueca Goitia: un arquitecto en la cultura española. Madrid: Fundación Antonio Camuñas, pp. 63-121.

Prieto Moreno, Francisco (1952). Los jardines de Granada. Madrid: Cigüeña.

Rovira Gimeno, Josep Maria (2006): "El Manifiesto de la Alhambra y su periferia: personajes, cultura y saberes colaterales". En: Isac, Ángel, ed.: El Manifiesto de la Alhambra 50 años después. El monumento y la arquitectura contemporánea. Granada: Patronato de la Alhambra y Generalife, TF Editores, pp. 127-181.

S.A. (1947): "Fernando Chueca Goitia. La Catedral de Valladolid". En: Boletín de Información de la Dirección General de Arquitectura, 5, Madrid, p. 40.

Tippey, Brett (2013): “Genuine Invariants: The Origins of Regional Modernity in Twentieth-century Spain". En Architectural History, 56. London, pp. 299-342.

Vázquez Rabanal, Alfredo (1974): "Informe sociológico sobre la profesión del arquitecto en el COAM". En: Arquitectura, 187-188, Madrid, pp. 71-90.

Fecha de recepción: 15-X-2014

Fecha de aceptación: 09-II-2015 